RESIDENT

\& FELLOW

SECTION

Section Editor

Mitchell S.V. Elkind,

MD, MS

Ritu Bagla, MD

John S. Khoury, MD

Christopher Skidmore, MD

Address correspondence and reprint requests to Dr. John Khoury, 900 Walnut St., Suite 200, Philadelphia, PA 19107 Jskhoury@gmail.com

\title{
Teaching Video NeuroImages: Dancing epilepsy
}

自

$\begin{array}{ll}\text { Figure } 1 & \text { Fluid-attenuated inversion recovery } \\ \text { coronal MRI revealed } \\ \text { encephalomalacia and gliosis in the } \\ \text { left frontal and right anterior } \\ \text { temporal regions }\end{array}$

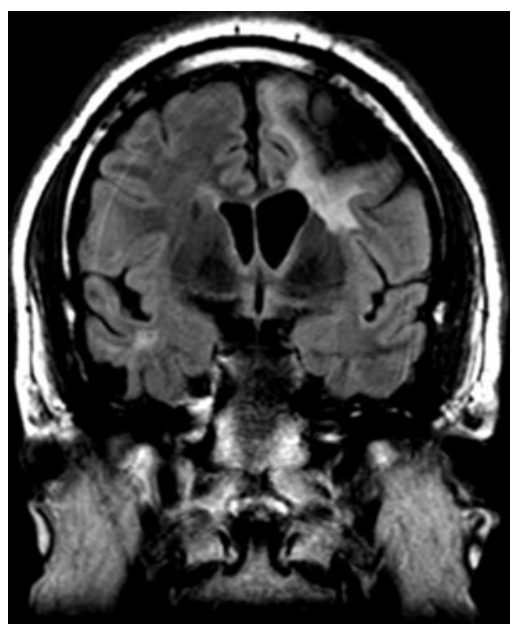

A 39-year-old, right-handed man with refractory complex partial seizures after head trauma at age 15 (figure 1) was admitted for video-EEG monitoring. His girlfriend describes dancing movements with unresponsiveness lasting a few minutes (see video). The interictal EEG was suggestive of a left temporal focus (figure 2); however, the ictal EEG was poorly localized and the overall localization was not determined. The dancing semiology is not typical of temporal lobe epilepsy, since automatisms involving proximal muscles and complex behaviors, such as bicycling, are suggestive of frontal lobe epilepsy. ${ }^{1}$ Dancing is another behavioral manifestation of epilepsy that has not been previously reported.

\section{REFERENCE}

1. Kotagal P, Arunkumar G, Hammel J, Mascha ED. Complex partial seizures of frontal lobe onset: statistical analysis of ictal semiology. Seizure 2003;12:268-281.

Figure 2 Interictal EEG

Supplemental data at www.neurology.org 